\title{
Interactive comment on "Combined effects of ozone and drought stress on the emission of biogenic volatile organic compounds from Quercus robur L." by Arianna Peron et al.
}

\section{Anonymous Referee \#1}

Received and published: 24 August 2020

This study focuses on the effect of simultaneous drought and ozone stress on emission of biogenic volatile organic compounds from Quercus robur $L$. The manuscript provides important information about the combined effect of drought and ozone exposure stressors. The finding that these stress factors are not always additive by itself is important, highlighting the need for additional study on the combined effects of multiple stressors. Yet, this notion is not novel (e.g., see references below). Some insights about the enzymatic pathways which were involved in the combined stress effects and the detailed information about the response of different BVOC types to different drought levels and combined stress effects can be useful for future study.

Printer-friendly version

Discussion paper 
Overall the manuscript is well written. In some cases, important methodological information is missing. I think that the Introduction lacks important explanation about the motivation of addressing your hypothesis on the basis of the key roles that BVOCs play in the troposphere. Specific comments are listed below.

Specific comments Line 20: please specify to what levels.

Line 26: "," should be placed after "Plants" and not after "in".

Line 48 "it has be shown" - please fix.

Line 49: Remove ",".

Line 51: "and longer growing longer seasons" - please rephrase.

Lines 51-54: However, drought can also lead to the opposite effect, as you mention below, which seems to be in conflict with this statement.

Line 87 - The hypothesis of this study is based on the research question whether drought and ozone stressors are additives. It would be good to expand more about 1) previous study of these two stressors in a broader scope (e.g., (Pollastrini et al., 2014; Wittig et al., 2007)) and 2) the importance of currently addressing this specific research question (e.g., how it can help scientists to cope with current assessment/research questions). 3) the state of knowledge with respect to BVOC emission (e.g., (Holopainen and Gershenzon, 2010)).

Line 87 - "different abiotic stresses" - be specific about whether you refer here only to ozone and drought stressors and/or to additional stressors.

Introduction- it will be good to provide information about the role of BVOCs in the troposphere.

Printer-friendly version

Lines 93-94 - " its fast-regulated transpiration rates "- This is not clear. I'm not sure that these two factors are sufficient to result in high tolerance to drought. 
Line 106- "air gas exchange" - Do you mean $\mathrm{CO} 2$ and $\mathrm{H} 2 \mathrm{O}$ exchange- please be specific in this definition throughout the text (e.g., line 119 and elsewhere). Can you elaborate on how did you measured this gas exchange?

I recommend adding the schematic of the experimental design (Fig. A1) to the Materials and Methods. It will help in following your experiments.

Lines 120-121 - please specify if this part still take place in the fitotron.

Line 131- Please define "rH".

Line 132- "assured" - can you explain in detail why it assures so?

Lines 135-136- Irradiation took place also in nighttime? Please specify.

Can you provide details about Background (zero) calibration? e.g., if and what frequency and under what conditions such calibration was performed using the PTRTOF6000X2?

Line 157 - it is not clear to me what do you mean by "combined calibration uncertainties" and by "a compound specific average experiment sensitivity".

Line 158 - "40-800 pptv" - it is not clear to me why providing this information is important. It may be more useful to specify specific limits of detection to individual compounds (possibly in Table A3).

Lines 161-168 - I suggest to include each individual compound acronym together with its specific $\mathrm{m} / \mathrm{z}$ (e.g., in parenthesis) and the specific reference, either in the text or in a table.

Line 179 - Why don't you include each of the abbreviations in parenthesis?

Line 189 - Can you elaborate on how the stomatal resistance was measured? Was it measured for each specific leaf or using another approach?

Printer-friendly version

Lines 189-190 - Can you explain why assuming that the boundary resistance is zero

Discussion paper 
is justified?

Line 197 - " (see below)" - it would be better to specify the specific section number.

Lines 203-204 - "peroxidase and antioxidant capacity, and phenol content" - it is the first time you mention these properties. It would be good to expand on them and why they were measured.

Line 216 - What do you mean by "linear range of. . ." ?

Line 256 - no need for multiple definition in the main text.

Line 260 - " significant." - can you add a P-value?

Line 274 - no need for multiple definition in the main text.

Line 285 - " (averagely $96 \%$ of the total emissions" - it would be better to provide this information earlier, so the reader will have this in mind when reading the second paragraph in this section.

Line 287 - "carbon loss ratio" - Be more accurate in definition. Do you mean->CIS/CA?

Line 288 -" high drought stress" - Can you specify this in terms of "R"?

Line 304 - Please add "." at the end of the sentence.

Lines 340-341 - "a decrease of MT emissions" - under what conditions?

Line 366- Is this a new paragraph (if so, make it clear and consistent with the rest of the manuscript)?

Lines 385-386 - " by stimulating the phenylpropanoid pathway" - what about the lipoxygenase and hydroperoxide systems?

Printer-friendly version

Line 396 - " well-watered and severe drought condition" - can you specify these also in terms of R?

Discussion paper

Tables 1 and 2 - it is recommended to include the comments below the table. Figure 
A1 - Can you include the thermocouple in the figure? What about

Table A3 - add the compound acronyms/names.

\section{References}

Holopainen, J. K., and Gershenzon, J.: Multiple stress factors and the emission of plant VOCs, Trends Plant Sci, 15, 176-184, 10.1016/j.tplants.2010.01.006, 2010. Pollastrini, M., Desotgiu, R., Camin, F., Ziller, L., Gerosa, G., Marzuoli, R., and Bussotti, F.: Severe drought events increase the sensitivity to ozone on poplar clones, Environ Exp Bot, 100, 94-104, 10.1016/j.envexpbot.2013.12.016, 2014. Wittig, V. E., Ainsworth, E. A., and Long, S. P.: To what extent do current and projected increases in surface ozone affect photosynthesis and stomatal conductance of trees? A meta-analytic review of the last 3 decades of experiments, Plant Cell Environ, 30, 1150-1162, 10.1111/j.13653040.2007.01717.x, 2007.

Interactive comment on Biogeosciences Discuss., https://doi.org/10.5194/bg-2020-260, 2020. 